\title{
Vernalização de cultivares de alho nobre na região de Lavras
}

\author{
Rovilson José de Souza; Fábio Silva Macêdo \\ UFLA, Depto. Agricultura, C. Postal 37, 37200-000 Lavras-MG; E-mail: rovilson@ufla.br
}

\begin{abstract}
RESUMO
Avaliou-se cultivares de alho nobre [Caçador 30, Caçador 40, Caçador, Caxiense, Chonan, Contestado, Gigante Núcleo, Quitéria e Quitéria obtida por cultura de tecidos $(\mathrm{CT})]$ submetidas à vernalização $\left(4^{\circ} \mathrm{C}\right)$ por 50 dias na região de Lavras (MG). O delineamento experimental utilizado foi blocos casualizados, com três repetições. Não foram observadas diferenças significativas entre as cultivares em relação à altura de plantas aos 60 dias após o plantio. A cultivar Caxiense apresentou a maior produção total de bulbos, diferindo estatisticamente das cultivares Caçador 30 e Contestado. As cultivares que apresentaram os menores índices de superbrotamento foram Chonan, Gigante Núcleo, Quitéria e Caçador. As cultivares Contestado e Caxiense apresentaram as maiores taxas de ocorrência desta anormalidade. As maiores produções comerciais de bulbos foram obtidas com as cultivares Quitéria e Caçador. Não foram observadas diferenças significativas de peso médio de bulbos e número de bulbilhos por bulbo da produção comercial entre as cultivares. A cultivar Gigante Núcleo apresentou maior peso médio de bulbilho da produção comercial quando comparada com as cultivares Contestado, Quitéria (CT) e Caçador 30, que não diferiram entre si.
\end{abstract}

Palavras-chave: Allium sativum, produção, superbrotamento.

\begin{abstract}
Vernalization of noble garlic cultivars in the region of Lavras, Brazil

Noble garlic cultivars were submitted to the vernalization $\left(4^{\circ} \mathrm{C}\right)$ during 50 days in the region of Lavras, Minas Gerais State, Brazil. The evaluated cultivars were Caçador 30, Caçador 40, Caçador, Caxiense, Chonan, Contestado, Gigante Núcleo, Quitéria and Quitéria obtained through tissue culture (CT). The experimental design was a complete randomized block, with three replications. No significant differences were observed in relation to plant height 60 days after planting date. Caxiense presented the highest total production of bulbs, differing significantly from the cultivars Caçador 30 and Contestado. The cultivars showing lesser indexes of secondary growth were Chonan, Gigante Núcleo, Quitéria and Caçador. Contestado and Caxiense presented the greatest percentages of bulbs with this abnormality. The highest commercial productions of bulbs were obtained with Quitéria and Caçador. No statistical differences in relation to average weight of bulbs and number of cloves per bulb were observed among the cultivars. Gigante Núcleo presented greater average weight of cloves when compared with Contestado, Quiteria (CT) and Caçador 30, that did not differ from each other.
\end{abstract}

Keywords: Allium sativum, production, secondary growth.

\section{(Recebido para publicação em 28 de setembro de 2003 e aceito em 14 de junho de 2004)}

A importância econômica da cultu a do alho tem aumentado sensivelmente nos últimos anos, não só pelo seu uso generalizado como condimento, mas também por algumas qualidades terapêuticas que a ele são atribuídas. As pesquisas têm mostrado resultados positivos para o incremento da produção como, por exemplo, cultivares mais adequadas para o plantio, vernalização de alhos nobres, ponto de colheita ideal, correto manejo da irrigação, armazenamento adequado, entre outros (Mota, 2003).

O fotoperíodo e a temperatura são fatores limitantes à bulbificação do alho, sendo que há diferenças entre cultivares quanto às exigências em fotoperíodo, (Bernardi e Igue, 1972).

A bulbificação do alho é favorecida pelo fotoperíodo longo e, uma vez recebido o estímulo, este poderá ser transmitido para outras partes da planta, que dará origem aos bulbilhos (Leopold e Kriedmann, 1975). Carvalho (1975), estudando os efeitos do fotoperíodo na bulbificação e crescimento do alho, cultivares 'Amarante' e 'Centenário', concluiu que os fotoperíodos mais longos antecipam o início de formação dos bulbos, reduzindo o ciclo da cultura. Pouco frio na fase inicial, muito frio na fase média, calor e dias longos na fase final do ciclo, são consideradas condições ideais (Regina, 1976).

A exposição dos bulbilhos à temperatura entre 0 e $10^{\circ} \mathrm{C}$ por um a dois meses aceleram a bulbificação, substituindo as exigências climáticas iniciais (Jones e Mann, 1983). Segundo Zing (1983), o tratamento a frio pré-plantio em alho antecipa a formação do bulbo, reduz o ciclo e quebra a dormência dos bulbilhos. Algumas cultivares, como Chonan, Caçador e Quitéria, necessitam de frigorificação pré-plantio de seus bulbilhos para que ocorra bulbificação em cultivo na região Sudeste. Esta técnica diminui a exigência fotoperiódica destas cultivares (Souza e Casali, 1986). Contudo, o artifício da frigorificação está fortemente relacionado com a indução do superbrotamento (Mann e Minges, 1958; Burba, 1983). O "superbrotamento" é uma anomalia genético-fisiológica que se caracteriza pela brotação antecipada dos bulbilhos antes da colheita. Os brotos novos crescem através do pseudocaule e emergem nas axilas das folhas, dando à planta o aspecto de uma ramificação abundante. É uma característica que influi negativamente na cultura do alho, pois além de reduzir a produtividade, deprecia o produto, fazendo com que o seu valor comercial seja comprometido (Souza e Casali, 1986).

Aoba e Takagi (1971) verificaram que plantas provenientes de bulbilhos frigorificados à temperatura de $5 \mathrm{a} 15^{\circ} \mathrm{C}$, por 20 a 30 dias, apresentaram bulbificação antecipada, sendo tanto maior o efeito quanto menor a temperatura e maior o tempo de tratamento. Nestas condições, Carvalho et al. (1980) observaram produção de bulbos de peso médio inferior aos obtidos nos tratamentos sem frigorificação. Resultados seme- 
lhantes foram obtidos por Rakhimbaev e Ol'shanskaya (1976) comparando bulbos armazenados a baixas temperaturas $(-2 o C \mathrm{a}+2 \mathrm{oC})$ e temperaturas mais elevadas (18oC a 20oC). Os autores constataram que, embora os bulbos tratados com baixas temperaturas fossem mais precoces, a produção foi menor e de qualidade inferior em relação aos bulbos armazenados em temperaturas mais elevadas.

O presente trabalho objetivou avaliar o desempenho produtivo de cultivares de alho nobre submetidas à vernalização na região de Lavras.

\section{MATERIAL E MÉTODOS}

O experimento foi conduzido de maio a outubro/2001, em condições de campo, na UFLA, localizada na latitude de $21^{\circ} 14^{\prime} \mathrm{S}$, longitude de $45^{\circ} 00^{\prime} \mathrm{W}$ e a uma altitude de $910 \mathrm{~m}$. O clima da região, segundo a classificação de Koeppen, é do tipo $\mathrm{Cwb}$, caracterizado por uma estação seca entre abril e setembro e por outra estação chuvosa, de outubro a março. $\mathrm{O}$ experimento foi conduzido em um Latossolo Vermelho Distroférrico.

Os tratamentos foram constituídos pelas cultivares Caçador-30, Caçador40, Caçador, Caxiense, Chonan, Contestado, Gigante Núcleo, Quitéria e Quitéria obtida por cultura de tecidos (CT). Os bulbos-semente da cultivar Caçador foram obtidos em uma propriedade de São Gotardo (MG) que já a plantava há seis anos, enquanto que as cultivares Caçador-30 e Caçador-40 foram recebidas de Santa Catarina. Os bulbos-semente das demais cultivares foram selecionados da multiplicação realizada pela UFLA. Os bulbos da cultivar Quitéria (CT) já haviam sido submetidos a cinco multiplicações. Os bulbos-semente de todas as cultivares foram submetidos à vernalização por 50 dias, em câmara com temperatura média de $4^{\circ} \mathrm{C}$.

$\mathrm{O}$ delineamento experimental utilizado foi blocos casualizados, com três repetições. Cada parcela ocupou $1 \mathrm{~m}^{2}$ de canteiro e foi constituída por cinco linhas de plantio, com dez plantas cada, sendo a área útil constituída pelas três linhas centrais e a bordadura pelas duas linhas laterais. Os bulbilhos foram plantados em 04/05/01 à profundidade de $5 \mathrm{~cm}$, com espaçamento de $10 \mathrm{~cm}$ entre plantas e $20 \mathrm{~cm}$ entre linhas. Foram utilizados para plantio os bulbilhos retidos na peneira 3 (malha $8 \times 17 \mathrm{~mm}$ ), apresentando peso médio de 2,3 g. Antes do plantio, os bulbilhos foram tratados com solução de Iprodione $(0,2 \%)$ para prevenir o ataque de patógenos de solo.

Dez dias antes do plantio foram aplicados $50 \mathrm{~kg} \mathrm{ha}^{-1}$ de N, $175 \mathrm{~kg} \mathrm{ha}^{-1}$ de $\mathrm{P}_{2} \mathrm{O}_{5}, 100 \mathrm{~kg} \mathrm{ha}^{-1}$ de $\mathrm{K}_{2} \mathrm{O}, 3 \mathrm{~kg} \mathrm{ha}^{-1}$ de B e $3 \mathrm{~kg} \mathrm{ha}^{-1}$ de $\mathrm{Zn}$, respectivamente, na forma de sulfato de amônio, superfosfato simples, cloreto de potássio, bórax e sulfato de zinco. A adubação de cobertura foi feita com $20 \mathrm{~kg} \mathrm{ha}^{-1}$ de $\mathrm{N}$, aos noventa dias após o plantio.

As daninhas foram controladas por capina manual sempre que necessário. Durante a condução do experimento observou-se a ocorrência de tripes (Thrips tabaci), ferrugem (Puccinia allii) e mancha púrpura (Alternaria porri), que foram controladas com pulverizações com produtos à base de monocrotofós, mancozeb e tebuconazole.

Usou-se aspersão convencional, sendo as irrigações efetuadas de dois em dois dias no primeiro mês após o plantio, e posteriormente de três em três dias. Aos cinqüenta dias após o plantio a irrigação foi suspensa por dez dias para diminuir os possíveis efeitos do superbrotamento na aparência e qualidade comercial dos bulbos. A irrigação também foi suspensa aos 95 dias após o plantio, quando as cultivares apresentaram início de secamento das folhas.

Colheu-se de agosto a outubro de 2001, de acordo com o ciclo vegetativo de cada cultivar, quando as plantas apresentavam apenas seis folhas verdes em início de secamento. Após a colheita, as plantas foram submetidas a uma pré-cura ao sol por três dias e curadas à sombra por 60 dias. Aos trinta dias após o início da cura, fêz-se o expurgo das plantas com fosfina na dosagem de duas pastilhas $/ \mathrm{m}^{3}$, visando o controle de pragas de armazenamento. Após a cura, processouse a toalete dos bulbos, sendo então anotados os dados de produção.

Foram avaliados: a) altura de plantas aos 60 dias após o plantio (distância entre o nível do solo até a extremidade da folha mais comprida), obtida de dez plantas ao acaso em cada parcela, anotando-se a média; b) produção total de bulbos (peso dos bulbos comerciais ou não, descartada a parte aérea, expresso em $\mathrm{kg} \mathrm{ha}^{-1}$ ); c) percentagem de bulbos superbrotados (contagem dos bulbos com três ou mais folhas superbrotadas após a cura, expressando os dados em relação ao número total de bulbos colhidos); d) produção comercial de bulbos (após seleção preliminar, eliminando-se bulbos chochos, superbrotados e não comerciais (menores que $32 \mathrm{~mm}$ de diâmetro), expressa em $\mathrm{kg} \mathrm{ha}^{-1}$; e) peso médio de bulbos comerciais (obtido pelo quociente entre o peso e o número de bulbos comerciais da parcela); f) número médio de bulbilhos por bulbo da produção comercial (contagem de bulbilhos de uma amostra de dez bulbos da produção comercial); g) peso médio de bulbilhos da produção comercial (obtido pelo quociente entre o peso e o número de bulbilhos da amostra de dez bulbos da produção comercial). Os dados foram submetidos à análise de variância e a comparação de médias foi feita pelo teste de Tukey a 5\% de probabilidade.

\section{RESULTADOS E DISCUSSÃO}

Não foram observadas diferenças significativas entre as cultivares em relação à altura de plantas aos 60 dias após o plantio (Tabela 1). A altura de plantas aos 60 dias após o plantio é, segundo Menezes Sobrinho et al. (1999), um dos parâmetros mais importantes e imprescindíveis na caracterização de cultivares. Mota (2003) avaliando a altura de plantas aos 70 dias após o plantio de cultivares de alho vernalizadas, verificou diferenças significativas, sendo que a cultivar Chonan apresentou porte inferior ao das cultivares Contestado, $\mathrm{Ca}$ çador 30 e Caçador 40, que não diferiram entre si.

A cultivar Gigante Núcleo apresentou o menor ciclo vegetativo (115 dias), seguida das cultivares Caçador, Chonan, Caçador 40 e Quitéria, com ciclo de 122 dias, Caçador 30 (129 dias), Contestado (138 dias) e Caxiense e Quitéria (CT), que apresentaram o maior ciclo (154 dias). Aalta taxa de superbrotamento nas cultivares Caxiense e Contestado (Tabela 1) pode ter contribuído para o alongamento do ciclo, já que as plantas permanecem verdes por um período maior. Por outro lado, as cultivares Gigante Núcleo, Caçador, Chonan e Quitéria, podem 
Tabela 1. Altura de plantas aos 60 dias após o plantio (AP), produção total de bulbos (PTB), percentagem de bulbos superbrotados (BS), produção comercial de bulbos (PCB), peso médio de bulbos comerciais (PB), número de bulbilhos por bulbo da produção comercial (NBB) e peso médio de bulbilhos da produção comercial $(\mathrm{Pb})$ de cultivares de alho nobres submetidas à vernalização. Lavras, UFLA, 2001.

\begin{tabular}{|c|c|c|c|c|c|c|c|}
\hline Cultivar & $\mathrm{AP}(\mathrm{cm})$ & PTB (Kg.ha-1) & BS (\%) & PCB (Kg.ha $\left.{ }^{-1}\right)$ & PB (g) & NBB & $\mathrm{Pb}(\mathrm{g})$ \\
\hline Caçador 30 & $59 a$ & $9383 \quad b$ & $20,1 \mathrm{abc}$ & $5883 a b$ & $21,4 \mathrm{a}$ & 9 a & $1,7 \quad b$ \\
\hline Caçador 40 & $61 \mathrm{a}$ & $12550 a b$ & $34,3 a b c$ & $7450 \mathrm{ab}$ & 30,8 a & 12 a & $2,5 a b$ \\
\hline Caçador1 & $43 a$ & $14667 a b$ & $4,2 a b$ & 11783 a & $33,4 \mathrm{a}$ & $13 \mathrm{a}$ & $2,6 a b$ \\
\hline Caxiense & $63 a$ & $18416 a$ & 44,4 bc & $9883 a b$ & 39,9 a & $13 \mathrm{a}$ & $2,8 a b$ \\
\hline Chonan & $59 a$ & $11117 a b$ & $0,0 \mathrm{a}$ & $9833 a b$ & $25,1 \mathrm{a}$ & $10 a$ & $2,4 a b$ \\
\hline Contestado & 56 a & 8583 b & $76,7 \quad c$ & $1383 b$ & $25,8 \mathrm{a}$ & $13 a$ & $2,0 \quad b$ \\
\hline Gigante Núcleo & $49 a$ & $11667 \mathrm{ab}$ & $0,0 \mathrm{a}$ & $10500 \mathrm{ab}$ & $28,3 \mathrm{a}$ & 8 a & $3,8 \mathrm{a}$ \\
\hline Quitéria & $65 a$ & $14783 a b$ & $0,0 \mathrm{a}$ & 14217 a & $32,9 \mathrm{a}$ & $11 \mathrm{a}$ & $2,8 a b$ \\
\hline Quitéria (CT)2 & $64 a$ & $13200 a b$ & $14,2 \mathrm{abc}$ & $9033 a b$ & $33,4 \mathrm{a}$ & 13 a & $1,8 \quad b$ \\
\hline CV (\%) & 21,0 & 22,8 & 50,3 & 39,0 & 27,1 & 22,8 & 19,8 \\
\hline
\end{tabular}

*/Médias seguidas de mesma letra nas colunas não diferem significativamente entre si pelo teste de Tukey a 5\% de probabilidade.

${ }^{1}$ Multiplicado em São Gotardo-MG; ${ }^{2} \mathrm{CT}=$ Multiplicação por cultura de tecidos

ter apresentado menor ciclo pelas suas baixas taxas de superbrotamento e por serem caracteristicamente mais precoces que as demais cultivares. Em trabalho desenvolvido por Seno et al. (1990) a cultivar Caçador apresentou ciclo de 100 dias, mostrando-se ainda precoce. Resende (1997a), em trabalho com a cultivar Quitéria, também observou maior precocidade em plantas provenientes de multiplicação convencional. Segundo o autor, as alterações metabólicas causadas pela infecção viral podem estar relacionadas com a antecipação da senescência da planta.

A cultivar Caxiense apresentou a maior produção total de bulbos, diferindo estatisticamente das cultivares Caçador 30 e Contestado (Tabela 1). Em trabalho realizado por Biasi e Mondardo (1999) em Caçador, a produção total de bulbos das cultivares Caçador 30 (5,7 t.ha- ${ }^{-1}$ ) e Contestado (7,0 t.ha $\left.{ }^{-1}\right)$ também foi baixa em relação às outras cultivares avaliadas. Apesar da variação de produtividade observada no presente trabalho, todas as cultivares avaliadas estão acima da média nacional que foi de 6,4 $\mathrm{t} \mathrm{ha}^{-1}$ no ano de 2000 (Agrianual, 2002).

As cultivares Chonan, Gigante Núcleo e Quitéria não apresentaram superbrotamento, diferindo estatisticamente das cultivares Contestado e Caxiense, que apresentaram altas taxas de superbrotamento (Tabela 1). Biasi e Mondardo (1999) também encontraram alta taxa de superbrotamento para a cultivar Contestado. Os autores consideraram que a vernalização foi prejudicial devido ao clima favorável à cultura no ano de condução do experimento. Segundo Biasi e Mueller (1989) a cultivar
Contestado, nas condições do sul do Brasil, produz de 10 a $18 \mathrm{t} \mathrm{ha}^{-1}$, com baixas taxas de superbrotamento. Em relação à cultivar Chonan, olericultores da região de São Gotardo relatam que esta cultivar apresenta plantas vigorosas e com alta incidência de superbrotamento, o que não foi observado nesse experimento. No caso do presente trabalho, pôde-se observar grande variabilidade entre as cultivares, em relação à ocorrência desta anormalidade, nas condições de clima e manejo em que o experimento foi conduzido. Dentre os diversos fatores que causam o superbrotamento, Filgueira (2000) aponta o excesso de água e de nitrogênio como sendo os principais. Além disso, deve-se considerar que as cultivares apresentam diferentes sensibilidades com relação a esta anormalidade. Devido à falta de informações específicas de manejo nas condições do sul de Minas Gerais para a maioria das cultivares avaliadas, a quantidade de água aplicada e as doses e datas de aplicação de nitrogênio foram iguais para todas as cultivares. Isso pode ter comprometido o desempenho de algumas cultivares, principalmente das que apresentaram maiores taxas de superbrotamento.

As cultivares Quitéria e Caçador apresentaram as maiores produções comerciais de bulbos (Tabela 1) e mostraram-se estatisticamente mais produtivas que a cultivar Contestado. $\mathrm{O}$ bom desempenho destas duas cultivares ocorreu principalmente devido às baixas taxas de bulbos superbrotados apresentadas por elas. Em trabalho realizado por
Farrapo et al. (2003) em Alfenas (MG) a cultivar Quitéria obtida por multiplicação convencional e por cultura de tecidos apresentou os piores desempenhos produtivos, enquanto que as cultivares Caçador e Chonan apresentaram os melhores resultados. Estas duas cultivares também se destacaram em experimento conduzido por Pereira et al. (2003) em Inconfidentes (MG), sendo que a cultivar Chonan apresentou a produção comercial de bulbos de 8,9 $\mathrm{t} \mathrm{ha}^{-1}$ e a cultivar Caçador o rendimento de $11,4 \mathrm{t} \mathrm{ha}^{-1}$, valores próximos aos encontrados no presente trabalho. Além disso, os autores também observaram baixos índices de superbrotamento para estas cultivares. Para a cultivar Caçador, vale ressaltar que o alho-planta utilizado no presente experimento vem sendo cultivado na região de São Gotardo há seis anos. Possivelmente passou por aclimatação natural neste período, o que pode ter contribuído para a baixa incidência de superbrotamento nesta cultivar. Por outro lado, os bulbos de Caçador 30 e Caçador 40, que foram recebidos diretamente de Santa Catarina, podem ter sido mais afetados em razão deste primeiro plantio na região. Em relação à cultivar Quitéria, é interessante observar que, quando proveniente de cultura de tecidos, observou-se a incidência de superbrotamento, não ocorrendo o mesmo com bulbos obtidos por multiplicação convencional. Segundo Rezende (1997a), plantas de alho provenientes de cultura de tecidos absorvem mais nitrogênio, o que pode promover maior taxa de superbrotamento, afetando com isso a produção comercial de bulbos. A alta 
taxa de superbrotamento apresentada pela cultivar Contestado comprometeu a sua produção comercial de bulbos, o que indica que deve ser uma cultivar merecedora de maiores cuidados principalmente quanto à irrigação e aplicações de nitrogênio. Silva et al. (1992) visando avaliar o desempenho produtivo de cultivares de alho vernalizadas em Baturité (CE), constatou que a cultivar Contestado apresentou a maior produção comercial de bulbos, mostrando potencial para aquela região. A cultivar Caxiense, que apresentou elevada produção total de bulbos, teve sua produção comercial bastante reduzida, pela alta taxa de superbrotamento. Como esta cultivar apresentou notadamente as plantas mais vigorosas do experimento, possivelmente a alta incidência de superbrotamento está associada ao excesso de água e/ou nitrogênio, devendo ser melhor estudada com relação a estes fatores.

Não foram observadas diferenças significativas entre as cultivares com relação ao peso médio de bulbos e número de bulbilhos por bulbo da produção comercial (Tabela 1). Mota (2003) verificou que o peso médio de bulbos comerciais da cultivar Chonan (29,3 g) foi superior ao da cultivar Contestado (20,5 g). No entanto, estas duas cultivares não diferiram estatisticamente de Caçador (28,6 g), Caçador 30 (24,8 g), Caçador $40(21,5)$ e Quitéria (24,1). Segundo Resende (1997b), devido às exigências do mercado consumidor, as maiores cotações a nível de comercialização recaem sobre cultivares que apresentam bulbos de maior tamanho e com pequeno número de bulbilhos. O pequeno número de bulbilhos por bulbo é uma característica atribuída aos alhos nobres. A portaria $\mathrm{N}^{\circ} 242 / 92$ do Ministério da Agricultura prevê que para pertencer a este grupo, o alho deve apresentar, dentre outras características, no máximo 20 bulbilhos por bulbo, o que foi observado em todas as cultivares avaliadas neste experimento.

A cultivar Gigante Núcleo apresentou o maior peso médio de bulbilhos da produção comercial, que foi significativamente superior ao das cultivares Contestado, Quitéria (CT) e Caçador 30 (Tabela 1). A diferença no peso médio de bulbilhos pode estar relacionada tanto à variabilidade genética entre as cultivares, quanto à procedência do material e forma de condução e manejo do experimento. $\mathrm{O}$ peso médio de bulbilho muito baixo pode restringir a sua aceitação no mercado consumidor, além de ser pouco desejável em bulbilhos que serão utilizados para plantio. Mueller et al. (1998), verificaram que com o aumento do peso dos bulbilhos-semente houve aumento na produção total e comercial de bulbos, redução do superbrotamento e aumento do peso médio de bulbos comerciais.

As cultivares Quitéria, Caçador, Gigante Núcleo e Chonan, nas condições de manejo e clima do experimento, se destacaram por apresentarem boas produções comerciais e baixas taxas de superbrotamento, além de boas características de bulbos e bulbilhos. A cultivar Caxiense apresentou a maior produção total de bulbos, porém, com alta taxa de superbrotamento, o que comprometeu a sua produção comercial de bulbos. Com isso, sugere-se que novos experimentos com esta cultivar sejam feitos com o objetivo de determinar o manejo mais adequado, principalmente com relação a aplicações de água e nitrogênio, para a diminuição das taxas de superbrotamento. A cultivar Contestado mostrou-se altamente sensível ao superbrotamento, apresentando o pior desempenho produtivo. Devem também ser melhor estudados os fatores que interferem na incidência do superbrotamento.

\section{LITERATURA CITADA}

AGRIANUAL 2002. Anuário da Agricultura Brasileira. São Paulo: FNP Consultoria e Comércio, 2002. 536 p.

AOBA, T.; TAKAGI, H. Studies on bulb formation in garlic plants III. The effects of cooling treatment of the seed bulb and of daylength during the growing period on bulb formation. Journal Japan Society for Horticultural Science, v.42, n.3, p.240241, 1971.

BERNARDI, J.B.; IGUE, T. Comportamento de cultivares de alho de curto e médio ciclo, na região de Campinas. Bragantia, Campinas, v.31, n.2, p.9-15, 1972.

BIASI, J.; MONDARDO,M. Desempenho do alho no Planalto Catarinense no plantio precoce, ano 1998/9. In: CONGRESSO BRASILEIRO DE OLERICULTURA, 39., 1999, Tubarão. Resumos... Brasília: SOB, 1999. p.274.

BIASI, J.; MUELLER, S. Alho Contestado. In: CONGRESSO BRASILEIRO DE OLERICULTURA, 29., 1989, Recife. Resumos... Brasília: SOB, 1989. p.43.

BURBA, J.L. Efeito do manejo do alho semente (Allium sativum L.) sobre a dormência, crescimento e produção da cultivar Chonan. Viçosa: UFV, 1983. 112 p. (Tese mestrado)

CARVALHO, C.G.S. Efeito de diferentes fotoperíodos na bulbificação e crescimento de duas cultivares de alho (Allium sativum L.). Viçosa: UFV, 1975, 43 p. (Tese mestrado)
CARVALHO, C.G.S.; MONNERAT, P.H.; CARVALHO, Y. Efeito de tratamentos pré-plantio de bulbilhos de alho (Allium sativum L.) cv. Amarante. Revista Latina de Ciência Agropecuária, v.15, n.1, p.165-173, 1980.

FARRAPO, G.H.; SILVA, E.C.; MACIEL, G.M. Cultivares de alho provenientes de Santa Catarina submetidos à vernalização artificial para cultivo na região de Alfenas-MG. In: CONGRESSO BRASILEIRO DE OLERICULTURA, 43., 2003, Recife. Resumos... Brasília: SOB, 2003. p.304. FILGUEIRA, F.A.R. Novo manual de olericultura: agrotecnologia moderna na produção e comercialização de hortaliças. Viçosa: UFV, 2000. 402 p.

JONES, M.A.; MANN, L.K. Onion and their allies. New York: Interscience, 1983. 286 p. LEOPOLD, A.C.; KRIEDMANN, P.B. Plant growth and development, 2a. ed. New York: McGraw Hill, 1975. 466 p.

MANN, L.K.; MINGES, P.A. Growth and bulbing garlic (Allium sativum L.) in reponse to storage temperature of planting stocks day length and planting date. Hilgardia, v.27, n.15, p.385-419, 1958. MENEZES SOBRINHO, J.A.; CHARCAR, J.M.; ARAGÃO, F.A.S. Caracterização morfológica de germoplasma de alho por análises multivariada componentes principais e variáveis canônicas. Horticultura Brasileira, Brasília, v.17, n.2, p.96101, 1999.

MOTA, J.H. Diversidade genética e características morfológicas, físicos-químicas e produtivas de cultivares de Allium sativum $L$. Lavras: UFLA, 2003. 66 p. (Tese doutorado)

MUELLER, S.; KREUZ, C.L.; MONDARDO, M. Produtividade, qualidade e lucro em função de espaçamento de plantio e pesos de bulbilhos-semente de alho. Agropecuária Catarinense, v.11, n.1, p.52-56, 1998.

PEREIRA, A.J.; SOUZA, R.J.; PEREIRA, W.R. Competição de cultivares de alho vernalizado na região de Inconfidentes-MG. In: CONGRESSO BRASILEIRO DE OLERICULTURA, 43., 2003, Recife. Resumos... Brasília: SOB, 2003. p.324. RAKHIMBAEV, I.R.; OL'SHANSKAYA, R.V. Dynamics of endognenous gibberellins during transition of garlic bulbs from dormancy to active growth. Fisiologye Rastneii, v.23, n.1, p.76-79, 1976.REGINA, S.M. Informações técnicas para a cultura do alho (Allium sativum $L$.). Belo Horizonte: ACAR, 1976. 37 p.

RESENDE, F.V. Crescimento, absorção de nutrientes, resposta à adubação nitrogenada e qualidade de bulbos de alho proveniente de cultura de tecidos. Lavras: UFLA, 1997a. 139 p. (Tese doutorado) RESENDE, G.M. Desempenho de cultivares de alho no norte de Minas Gerais. Horticultura Brasileira, Brasília, v.15, n.2, p.127-130, 1997b.

SENO, S.; SASAKI, J.L.S.; KIMOTO, T. Comportamento de cultivares de alho na região de Ilha Solteira-SP. In: CONGRESSO BRASILEIRO DE OLERICULTURA, 30., 1990, Campo Grande. Resumos... Brasília: SOB, 1990. p.66.

SILVA, L.A.; MUNIZ, J.O.L.; GOMES, C.C.; BIASI, J. Influência da frigorificação pré-plantio sobre o comportamento de cultivares de alho na região de Baturité-CE. In: CONGRESSO BRASILEIRO DE OLERICULTURA, 32., 1992, Aracaju. Resumos... Brasília: SOB, 1992. p.69. SOUZA, R.J.; CASALI, V.W.D Pseudoperfilhamento: uma anormalidade genético- fisiológica em alho. Informe Agropecuário, Belo Horizonte, v.12, n.142, p.36-41, 1986.

ZING, F.W. Tate of growth and nutriente absorption of late garlic. Proceedings of the Americam Society for Horticultural Science, v.83, p.579-584, 1983. 